\title{
The Effect of Breathing Exercise on Stress Hormones
}

\author{
() Deniz Örün1, (1) Selma Karaca22, (1) Șükran Arıkan2 \\ 1 Ladik Ahmet Hüdai Imam Hatip Secondary School, Konya, Turkey \\ 2Department of Coaching Education, Selçuk University Faculty of Sport Sciences, Konya, Turkey
}

\section{Abstract}

BACKGROUND/AIMS: The aim is to determine the acute effects of breathing exercise on stress hormones in young women.

MATERIALS and METHODS: The study was conducted with the voluntary participation of 15 healthy young women who were working as coaches in the fitness and swimming branches. At the beginning of the study, the body compositions of the participants were determined, and 45-minute natural and connected breathing exercise was applied under the supervision of a breathing coach after having a standard breakfast. Cortisol and epinephrine hormone analyses from the serums was obtained from the blood samples taken before and after the breathing exercise were determined through a Chemiluminescence measurement method. Whether the data showed a normal distribution was analyzed through Kolmogorov-Smirnov test and paired t-test, since parametric test conditions were fulfilled. The relationship between the variables were determined with a Pearson correlation analysis.

RESULTS: At the end of an acute breathing exercise, a significant decrease was determined in the mean cortisol hormone levels of the participants $(p<0.05)$. A decrease was observed in the epinephrine hormone levels; however, this change was not found to be statistically significant ( $p$ $>0.05$ ). In addition, it was determined that there was a positive and considerably weak insignificant relationship between the mean cortisol and epinephrine of the participants following the breathing exercise $(r=0.039 ; p>0.05)$.

CONCLUSION: It could be stated that natural and connected breathing exercise has a reducing effect on stress hormones, and accordingly, breathing exercises could be used as a relaxation technique.

Keywords: Breathing exercise; cortisol; epinephrine

\section{INTRODUCTION}

Life is the period between the first breath and the last one. While breathing is behavioral and respiration is reflexive; therefore, breathing and respiration are not the same phenomenon. ${ }^{1}$ Breathing is based on the energy flow by moving downward/ upward, expanding/narrowing of the chest and abdomen area in the physical body, and how this flow affects our bodies physically, mentally and spiritually. ${ }^{2}$

According to Greek mythology" PNEUMA," (i.e., breath, is our primary activity that accompanies us in every aspect of our lives and enables us to survive healthily for quality life). ${ }^{3}$ Behavioral or voluntary control of breathing is located on the cerebral cortex. While voluntary breathing requires the amount of focus, attention is not necessary to maintain an automatic (metabolic) breathing. ${ }^{4}$ While breathing regulates $\mathrm{pH}$, electrolyte balance, blood flow, hemoglobin chemistry, and kidney function, it also has a significant effect on other behaviors such as motivation, strength, emotion, focus, perception, and memory role. ${ }^{5}$

Breathing techniques, which are expressed as pranayama applied in different variations in the form of conscious, intermittent, nasal, and abdominal breathing where upper, middle, and

To cite this article: Örün D, Karaca S, Arıkan \$̦. The Effect of Breathing Exercise on Stress Hormones. Cyprus J Med Sci 2021;6(Suppl 1):22-27

ORCID iDs of the authors: D.Ö. 0000-0003-0537-9788; S.K. 0000-0002-0897-6900; S..A. 0000-0002-2625-0898. 
lower parts of the lung are used. ${ }^{6}$ Breathing techniques are regularly applied for relaxation, stress management, control of psycho-physiological states, and to improve the organ functions. ${ }^{7}$ Although there are many sources for stress, it also varies from individual to individual. ${ }^{8}$ Psychological studies revealed breathing practice as an effective non-pharmacological intervention for emotional improvement including anxiety, depression, and stress. ${ }^{9}$ In addition, breathing practices are also commonly applied in the clinical treatments for mental disorders such as post-traumatic stress disorder, ${ }^{10}$ movement disorders, ${ }^{11}$ phobias, and other stress-related emotional disorders.

Prana is particularly associated with an energy production processes in the body. There is a direct connection between the breathing energy and energy release from the body. ${ }^{12}$ With a proper breathing, improvements could be experienced in energy centers of the body. The first energy center is located below the abdomen near the center of the gravity, and this center controls vital energy and certain hormones. The proper functioning of this center strengthens the immune system and increases the overall life energy. ${ }^{13}$ Scientists have been reported that the daily energy needs could be met by taking the deep breaths for 15 mins. However, most people use energy potential in a limited way because they do not know use the power of breath that will enable them to achieve these benefits. ${ }^{14}$ Studies report that slow and rapid breathing types have different physiological effects in the healthy subjects. ${ }^{15}$

Epinephrine and cortisol hormones known as stress hormones, are secreted by the adrenal glands. Epinephrine hormone alerts the body by being secreted in the dangerous situations such as exercise, lack of oxygen, excitement, fear, excessive heat decrease, anger, and sudden decrease in the blood sugar levels. The roles of epinephrine are to increase the blood pressure, heart rate and the blood circulation, depth of respiration, and blood glucose level. Cortisol hormone, which belongs to the glucocorticoid class, increases the blood glucose level by accelerating the synthesis of glucose from the protein and fat in the liver. It accelerates the burning of triglycerides and causes an increase in the concentration of free fatty acids in the blood, and it also has anti-inflammatory effects. ${ }^{16}$

Stress caused by the physiological or psychological conditions could be expressed as the sum of reactions of a person to the various mental and physical difficulties. ${ }^{8}$ Nervousness, impatience, anger, hostility, anxiety, panic, restlessness, sadness, tension, poor memory, difficulty in taking the decisions, hypersensitivity, change in the sexual life, frequent daydreaming, frequent repetitions of death and suicidal thoughts, sleep disorders, depression, increase in the alcohol intake and substance use, decrease in the self-esteem and productivity are the psychological symptoms of the stress. ${ }^{17}$

Stress may have many psychological and physiological causes. The environment in which we live, our body and even our world of thoughts could be a trigger factor for stress. However, people physiologically tend to cope up with the stress and react to it. In this context, the cortisol hormone plays a very important role in a stress response. One of the important hormone response systems to stress is cortisol -hypothalamic-pituitary-adrenal (HPA) axis, especially the glucocorticoids. ${ }^{18}$ Within this context, stressors stimulate cortisol secretion from the adrenal gland by affecting the hypothalamus. With the mixing of cortisol into the blood, a stress response occurs in the body. ${ }^{19}$ Stressors have a huge impact on the mood, sense of well-being, behavior, and health. In the presence of a physical or psychological threat, cortisol levels fluctuate to provide the energy needed to cope up with the stress-inducing stimuli or escape danger. ${ }^{20}$

Stress in daily life could cause physical, emotional, behavioral, and psychological problems as well as chronic illness. Therefore, it is very important for individuals to learn how to live with stress, and to know how to manage the stress to minimize its negative effects. In the study, answers to the questions such as "what is the effect of breathing exercise on stress hormones," "Does the stress hormone level decrease with breathing exercise?" were sought. The limited number of studies in the literature conducted on how breathing exercises affect the stress hormone levels motivated us to carry out this study. This research aimed to determine the acute effects of breathing exercises applied to young women on epinephrine and cortisol hormones.

\section{MATERIALS AND METHODS}

\section{Research Group}

A total of 15 healthy and voluntary young women aged between 20-35 and working as coaches in the different branches in Konya province, Selçuklu Municipality Social Facilities participated in this research. Prior to the study, the subjects were informed about the study and their written informed consents to participate in the research were obtained. The questionnaire prepared by the researcher was applied to determine the demographic characteristics, physical activity levels, and general health conditions of the participants. For this study, approval was obtained from Selçuk University Faculty of Sports Sciences Non-Interventional Clinical Research Ethics Committee on December 20, 2018.

Inclusion criteria: Having no health problems that would prevent the participant from doing breathing exercises. Being in the age range of 20-35. Exclusion criteria: Having a systemic pathology. Using medication/drugs that may affect the hormone levels.

\section{General Design of the Research}

All measurements and breathing exercise were made on January 23, 2019 at the Selçuklu Municipality Gazalya Hatun Social Facility. Body composition measurements of the subjects were performed after a standard breakfast while the blood samples 
were taken before and after the acute exercise under the equal conditions. To reveal the effect of an exercise on biochemical variables, subjects were warned not to perform heavy physical activities at least 48 hours before, and not to use any drug or liquid food that could affect the values.

\section{Determination of Body Composition}

The body weights $(\mathrm{kg})$ of the subjects were measured with Tanita device and their heights $(\mathrm{cm})$ were measured with a metal meter with $0.01 \mathrm{~cm}$ precision. Participants' body mass index (BMI) was calculated by dividing the body weight $(\mathrm{kg})$ in the square of height $(\mathrm{m}) .{ }^{21}$ Participants' fat mass, lean body mass, and fat percentage values were measured with BC-418 MA model Tanita device (1-14-2, Maeno-cho, İtabashi-ku, Tokyo, Japan) through the bio-electrical impedance analyzer technique.

\section{Breathing Exercise}

One week before the acute breathing exercise planned for the research, the participants were informed by a breathing coach who had received the training on natural and connected breathing, and a practice session was performed to apply the technique correctly. One week after this application, all the participants were subjected to a breathing session on the same day and at the same time. Breathing session was started after the participants were in the sitting position with their soles on the grounds, knees bent, and bodies back at a $45^{\circ}$ angle. With the guidance of the coach, the participants were enabled to stay in a natural and connected breathing without a break in an uninterrupted and continuous way. The participants were enabled to breathe through the mouth for 45 mins by using the diaphragm and chest, respectively.

\section{Biochemical Blood Analyses}

All participants of the research were asked to have a light standard breakfast at least 2 hours before coming for the exercise. Blood samples were taken from the forearm elbow vein into the

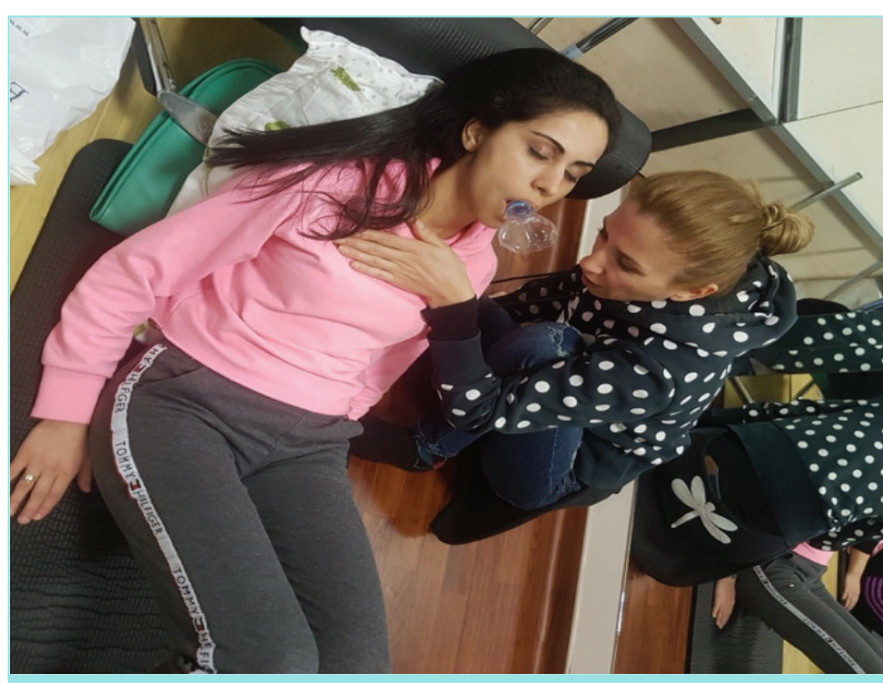

Figure 1. Breathing exercise. vacutainer blood collection tubes with a gel and anticoagulant $(6 \mathrm{cc})$ by the health personnel at 08:00 a.m. before and after the breathing exercise. Blood samples were centrifuged at $+4^{\circ} \mathrm{C}$ and 4,000 rpm for 10 mins and their serums were obtained, and they were frozen at $-20^{\circ} \mathrm{C}$ until the analyses is being done. From the serum samples, cortisol and epinephrine hormone levels were determined with Chemiluminescence measurement method in Abbott Architect 12000 analyzer (Abbott Labs, Chicago, Illinois, USA) and epinephrine hormone levels were determined with the same method but in Shimadzu LC-20A HPLC device (Shimadzu Corp, Kyoto, Japan).

\section{Statistical Analysis}

SPSS 22.0 (SPSS Inc., Chicago, IL, USA) packaged program was used in the analysis of the data. Arithmetic means and standard error mean of all the variables obtained in the study were calculated. Kolmogorov-Simirnov test was used to determine whether the data showed a normal distribution. As a result of the test, it was determined that the data showed a normal distribution and paired t-test was applied to reveal the differences between the measurements performed on the same group at two different times. The relationship between the variables was determined through Pearson correlation analysis and the results were evaluated at 95\% confidence interval and $p<0.05$ significance level.

\section{RESULTS}

The mean age of the participants was found to be $29.06 \pm 4.26$ years, height $163.66 \pm 3.81 \mathrm{~cm}$, body weight $54.98 \pm 4.97 \mathrm{~kg}$, fat percentage $24.20 \pm 4.23$, and mean BMI $20.55 \pm 1.78 \mathrm{~kg} / \mathrm{m}^{2}$ (Table 1).

A significant decrease was observed in the mean cortisol hormone levels of the participants before and after the breathing exercise $(p<0.05)$. When the responses of epinephrine hormone were examined, it was seen that there was a decrease in the hormone levels, but this decrease was not found to be statistically significant $(p>0.05)$ (Table 2).

A positive and considerably weak insignificant relationship was determined between the mean cortisol and epinephrine of the participants following the breathing exercise $(r=0.039 ; p>0.05)$.

Table 1. Results related to the participants' mean age, height, body weight, and body mass index

\begin{tabular}{|l|l|l|l|l|l|}
\hline Variables & $\mathbf{n}$ & Min & Max & $\overline{\mathbf{X}}$ & SD \\
\hline Age (year) & 15 & 24.00 & 35.00 & 29.06 & 4.26 \\
\hline Height $(\mathrm{cm})$ & 15 & 159.00 & 171.00 & 163.66 & 3.81 \\
\hline Body weight $(\mathrm{kg})$ & 15 & 47.60 & 62.50 & 54.98 & 4.97 \\
\hline Fat $(\%)$ & 15 & 16.70 & 31.20 & 24.20 & 4.23 \\
\hline BMI (kg/m²) & 15 & 17.00 & 23.50 & 20.55 & 1.78 \\
\hline Min, Minimum; Max, Maksimum; SD, Standard deviation; n, Number.
\end{tabular}




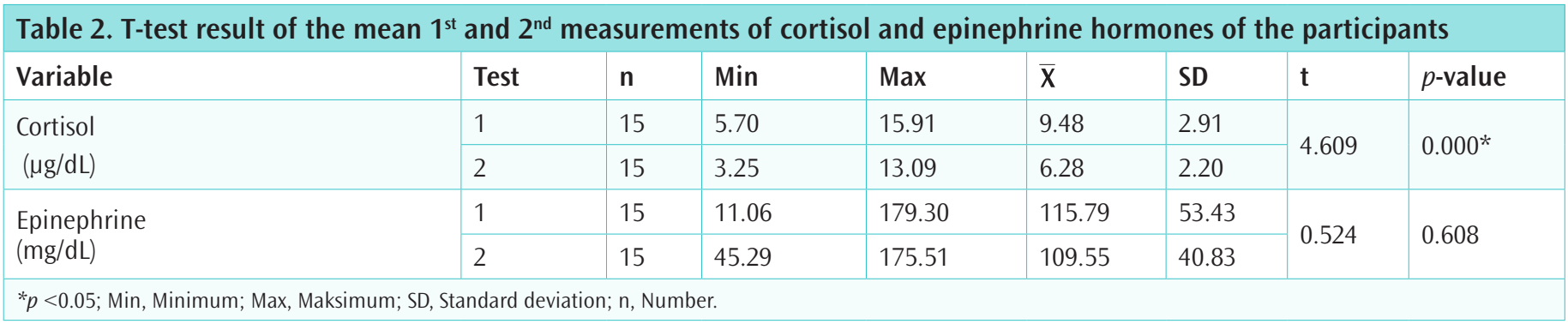

\section{DISCUSSION}

The most important finding of this study conducted to determine the effects of the breathing exercises on some stress hormones, is that epinephrine and cortisol hormone levels decreased after an acute breathing exercise; however, while this change was significant in cortisol hormone, it was not found in epinephrine hormone. Moreover, there was a positive and highly weak insignificant relationship between the stress hormones.

The control mechanisms of the body are the nervous system and endocrine system. These two systems are responsible for the regulation of the body's physiological and psychological processes. Like the increase in the happiness hormone levels when feeling happy and stress hormone levels when feeling stressed and nervous, mood state may also change with the effect of hormones psychologically. Stress is accepted as a condition in which emotional and psychological components are no longer in harmony with the physical components of health. If this condition is perceived and evaluated by the brain as danger, stress reaction begins to function. Some subcortical areas are activated in the brain, and they try to regulate the normal function of the body. The first activated system is the hypothalamus, and it immediately begins to secrete hormones. The effects of stress are not only limited to psychological components; stress also changes the levels of various hormones. ${ }^{22}$

Cortisol hormone is a reliable indicator stress. ${ }^{23}$ In addition, cortisol is a hormone that could involuntarily control some of the mental processes including metabolism, immunity, memory, and emotional evaluation, and is easily affected from the breathing excercises. ${ }^{24}$ The second system is the secretion of epinephrine hormone from the adrenal medulla through the sympathetic nervous system. Both systems are useful in managing the temporary stress, protective and supportive in the tissues. $^{8}$

Janakiramaiah et al. ${ }^{25}$ interpreted that the plasma cortisol level remained stable after the first yoga breathing session applied to the dysthymic patients, and the breathing experience was not stressful. It is foreseen that sudarshan kriya yoga, which is a special series of respiration techniques, may relieve anxiety, depression, daily stress, post-traumatic stress, and stressrelated medical diseases, and may be a useful, low-risk, and low-cost supplementary treatment for substance abuse and the rehabilitation of the criminals (26). Evidence obtained from the randomized controlled study shows that a seven-day intensive yoga program with pranayama, (i.e., breathing exercises), reduces anxiety and depression in patients with a chronic low back pain. ${ }^{27}$ Like this study, Kharya et al. ${ }^{28}$ concluded that controlled breathing exercises, including the Sudarshan Kriya and PranaYoga, positively changed stress coping with the behavior and initiated an appropriate balance in the cardiac autonomic tone.

Veerabhadrappa et al. ${ }^{29}$ detected a significant decrease in the Beck Depression Inventory score after a two-week breathing exercise to determine the antidepressant efficiency and hormonal effects of the yogic breathing technique on alcohol addicts. As a result of this study, it was stated that this improvement in the psychological condition may have been caused by the significant decrease in the cortisol levels. In another study, it was reported that a breathing exercise of five minutes and 30 sessions per day could significantly reduce the anxiety in pregnant women who experienced preterm labor. ${ }^{30}$ Salyers et al. ${ }^{31}$ emphasized that a one-day breathing exercise relieved an emotional exhaustion, and depersonalization caused by occupational burnout. In a study conducted to determine the effects of the diaphragmatic respiration on exercise-induced oxidative stress and the potential role of the cortisol hormone in this stress condition, it was found that diaphragm breathing applied after an intensive training increased the antioxidant defense status, and this situation resulted from the decrease in the cortisol level. ${ }^{32}$ Naik et al. ${ }^{22}$ reported that there was a significant decrease in the resting heartbeat rate, systolic and diastolic blood pressure, and perceived stress conditions of 100 male volunteers who performed slow and deep breathing exercise for 30 minutes 5 -times a week for 12 weeks, and it was effective in the improvement of the cardiovascular parameters.

It is emphasized that a rhythmic and controlled breathing type, which includes cyclic breathing where medium and short breath followed by a long breath, may play an important role in promoting the healthy lifestyle by improving the immune system, antioxidant condition, hormonal condition, and the brain function. ${ }^{33}$ The mechanism through which breathing exercises are thought to reduce stress is a decrease in the serum cortisol levels as well as a direct decrease in the sympathetic 
activity which enables the domination of a parasympathetic tone. Decreased cortisol levels are related with an increased sense of happiness, decreased anxiety, and an increased threshold for stress perception. ${ }^{34}$

When the above-mentioned studies are examined, it is observed that the studies examining the responses of the breathing exercises to stress hormones mostly include special yoga breathing sessions for psychological and therapeutic purposes. ${ }^{15,25,27,28,30}$ In the present study, unlike the other studies, an acute effect of a breathing exercise performed by the healthy individuals on epinephrine and cortisol hormones was examined. Our study differs from other studies in this respect.

\section{Limitations of the Study}

This research has some limitations; all female participants included in this research were examined in terms of stress hormones because of only one breathing exercise; however, the effects of the age groups, gender, and different breathing exercises could not be examined. The absence of a control group is one of the limitations of this study, as there were not enough participants with the same conditions in the study, and therefore, it was not possible to compare the breathing exercise group with a control group. The pre-exercise values of the experimental group were accepted as the basic values by making a comparison within the group. In the new studies to be carried out, experiment and control groups could be formed and the difference between the groups may be evaluated. Furthermore, blood samples were taken as a single sample before and after the exercise at the morning hours. However, since the day and night rhythms of the hormones differ during the day, not taking samples at certain intervals may have been affected the results of the study.

\section{CONCLUSION}

Cortisol is secreted in a pulsatile manner. In humans, cortisol secretion has a circadian rhythm, and the cortisol concentration reaches its peak level during the morning hours. ${ }^{35}$ Later, cortisol gradually declines in the body during the day until evening. Since our research aim was to determine the effect of an acute breathing exercise on the stress hormones, cortisol levels during the day could not be measured. This is one of the limitations of the research. Therefore, considering this limitation, the morning hour, which is stated to have a high cortisol secretion, was preferred to see the effect of the breathing exercise. The significant decrease in the cortisol levels after 45 mins of breathing exercise is thought to have stemmed from breathing exercise. As a matter of fact, cortisol is a hormone that is easily affected by breathing. ${ }^{24}$ In other studies, indicating that breathing exercises reduces the cortisol levels, there have been references supporting our study results. $25,29,32,34$
As a result, it was determined that an acute breathing exercise decreased stress hormone levels. Considering the long-term effects of breathing exercise, it could be stated that it has healing effects in non-pharmacological areas in terms of balancing the emotions and managing stress.

\section{Main Points}

- Breathing is based on an energy flow that is much more than moving downward/upward, expanding/narrowing of the chest and abdomen area in the physical body and how this flow affects our bodies physically, mentally, and spiritually. As a vital function, respiration is not regulated by the certain hormones but is affected by a wide variety of hormones. Breathing techniques are regularly applied for relaxation, stress management, control of psycho-physiological states and to improve the organ function.

- The aim of this study is to determine the acute effects of breathing exercise on stress hormones in young women.

- It could be stated that natural and connected breathing exercise has a reducing effect on stress hormones, and accordingly, breathing exercises could be used as a relaxation technique.

\section{ETHICS}

Ethics Committee Approval: For this study, approval was obtained from Selçuk University Faculty of Sports Sciences Non-Interventional Clinical Researches Ethics Committee on 20.12.2018 with the decision number of 65 .

Informed Consent: All subjects gave their informed consent for inclusion before they participated in the study.

Peer-review: Externally peer-reviewed.

\section{Authorship Contributions}

Concept: D.Ö., S.K., Ş.A; Design: D.Ö., S.K., S..A.; Supervision: D.Ö., S.K.; Fundings: S.K.; Materials: D.Ö.; Data Collection and/or Processing: D.Ö.; Analysis and/or Interpretation: S.K.; Literature Search: D.Ö., S.K., S.A.; Writing: D.Ö., S.K., S..A.; Critical Review: S.A.

\section{DISCLOSURES}

Financial Disclosure: This study was supported by the Selçuk University Scientific Research Projects (S.U. BAP, Konya, Turkey) (project no: 19401116).

Conflict of Interest: The authors declare no conflict of interest.

\section{REFERENCES}

1. Litchfield PM. A brief overview of the chemistry of respiration and the breathing heart wave. Equine Breathing. 2003;19:1-6. Available at: https:// www.equinebreathing.com/uploads/Files/peter_lichfield_physiology_of_ respiration.pdf 
2. Sinik E. Nefeste Saklı Hayat, Libros Yayıncılık. 6. Basım, İstanbul 2017;71160.

3. Acar N. Nefes Kullanımı ve Şan Eğitimi. Ulakbilge. 2016;4:231-236.

4. Gallego J, Nsegbe E, Durand E. Learning in respiratory control. Behav Modif. 2001:25:495-512.

5. Laffey JG, Kavanagh BP. Hypocapnia. N Eng/ J Med. 2002;347:43-53.

6. Collins C. Yoga: Intuition, preventive medicine and treatment. J Obstet Gynecol Neonatal Nurs. 1998;27:563-568.

7. Ritz T, Roth WT. Behavioral intervention in asthma. Behav Modif. 2003; $27: 710-730$

8. Balcıoğlu I. Savrun M. Stress and hormone. J Psychiatry. 2001;2:43-50.

9. Stromberg SE, Russell ME, Carlson CR. Diaphragmatic breathing and its effectiveness for the management of motion sickness. Aerosp Med Hum Perform. 2015;86:452-457.

10. Goldin PR, Gross JJ. Effects of mindfulness-based stress reduction (MBSR) on emotion regulation in social anxiety disorder. Emotion. 2010;10:83-91.

11. Russell MEB, Hoffman B, Stromberg S, Carlson CR. Use of controlled diaphragmatic breathing for the management of motion sickness in a virtual reality environment. Appl Psychophysiol Biofeedback. 2014;39:269-277.

12. Jerath R, Edry JW, Barnes VA, Jerath V. Physiology of long pranayamic breathing: Neural respiratory elements may provide a mechanism that explains how slow deep breathing shifts the autonomic nervous system. Med Hypotheses. 2006;67:566-571.

13. Nefes Kitabı ŞC. Klan yayıncılık, İstanbul, 2017; pp. 10-15.

14. Vas LSR. İileștiren Nefes nefesin iyileștirici, huzur verici ve aydınlatıcı gücünü kullanmak, Akașa yayınları, 2014

15. Vedamurthachar A, Janakiramaiah N, Hegde JM, et al. Antidepressant efficacy and hormonal effects of sudarshana kriya yoga (SKY) in alcohol dependent individuals. J Affect Disord. 2006;94:249-253.

16. Günay M, Tamer K, Cicioğlu G. Spor fizyolojisi ve performans ölçümü. 3. Baskı, Ankara, Gazi Kitabevi, 2013; pp. 245-257.

17. Özel Y. Bay Karabulut A. Günlük yaşam ve stres yönetimi. Turkiye Klinikleri J Health Sci. 2018;1:48-56.

18. Stephens MAC, Wand G. Wand G. Stress and the HPA axi: Role of glucocorticoids in alcohol dependence. Alcohol Res. 2012;34:468-483.

19. Yiallouris A, Tsioutis C, Agapidaki E, et al. Adrenal aging and its implications on stress responsiveness in humans. Front Endocrinol. 2019;10:54.

20. Hannibal KE, Bishop MD. Chronic stress, cortisol dysfunction, and pain: A psychoneuroendocrine rationale for stress management in pain rehabilitation. Phys Ther. 2014;94:1816-1825.
21. Mackenzie B. 101 Performance evaluation tests. Electric world plc, London 2005; pp. 96

22. Naik GS, Gaur GS, Pal GK. Effect of modified slow breathing exercise on perceived stress and basal cardiovascular parameters. Int / Yoga. 2018;11:5358.

23. Feder A, Nestler EJ, Charney DS. Psychobiology and molecular genetics of resilience. Nat Rev Neurosci. 2009;10:446-457.

24. Matousek RH, Dobkin PL, Pruessner J. Cortisol as a marker for improvement in mindfulness- based stress reduction. Complement Ther Clin Pract. 2010;16:13-19.

25. Janakiramaiah N, Gangadhar BN, Naga Venkatesha Murthy PJ, Harish MG, Subbakrishna DK, Vedamurthachar A. Therapeutic efficacy of Sudarshan kriya yoga (SKY) in dysthymic disorder. Nimhans J. 1998;17:21-28.

26. Zope SA, Zope RA. Sudarshan Kriya Yoga: Breathing for health. Int J Yoga. 2013;6:4-10

27. Tekur P, Nagarathna R, Chametcha S, Hankey A, Nagendra HR. A Comprehensive yoga programs improves pain, anxiety and depression in chronic low back pain patients more than exercise: An Rct Complement Ther Med. 2012;20:107-118.

28. Kharya C, Gupta V, Deepak KK, et al. Effect of controlled breathing exercises on the psychological status and the cardiac autonomic tone: Sudarshan Kriya and Prana-Yoga. Indian J Physiol Pharmacol 2014;58:211-221.

29. Veerabhadrappa SG, Baljoshi VS, Khanapure S, et al. Effect of yogic bellows on cardiovascular autonomic reactivity. J Cardiovasc Dis Res 2011;2:223-227.

30. Chang SB, Kim HS, Ko YH, Bae CH, An SE. Effects of abdominal breathing on anxiety, blood pressure, peripheral skin temperature and saturation oxygen of pregnant women in preterm labor. Korean J Women Health Nurs. 2009;15:32-42.

31. Salyers MP, Hudson C, Morse G, et al. BREATHE: A pilot study of a one-day retreat to reduce burnout among mental health professionals. Psychiatr Serv. 2011;62:214-217.

32. Martarelli D, Cocchioni M, Scuri S, Pompei P. Diaphragmatic breathing reduces exercise-induced oxidative stress. Evid Based Complement Alternat Med. 2011;2011:932430

33. Sharma P, Thapliyal A, Chandra T, Singh S, Baduni H, Waheed SM. Rhythmic breathing: Immunological, biochemical and physiological effects on health. Adv Mind Body Med. 2015;29:18-25.

34. McCall M. How might yoga work? An overview of potential underlying mechanisms. J Yoga Phys Ther. 2015;3:2-4.

35. Tomas C, Newton J, Watson S. A review of hypothalamicpituitary-adrenal axis function in chronic fatigue syndrome. ISRN Neurosci. 2013;2013:1-8. 